\title{
Erratum to: Role of Transesophageal Echocardiography in General Anesthesia
}

\author{
Jacobo Moreno Garijo ${ }^{1}$ - Azad Mashari ${ }^{1}$ - Massimiliano Meineri ${ }^{1}$
}

Published online: 12 August 2017

(C) Springer Science+Business Media, LLC 2017

\section{Erratum to: Curr Anesthesiol Rep}

\section{DOI 10.1007/s40140-017-0221-x}

The original version of this article unfortunately contained a mistake. The reference citation "[4•]" under the sections "Central Venous Pressure," "Pulmonary Artery Pressures," and "Pulmonary Capillary Wedge Pressure" should be reference number "[5•]".

The authors apologize to readers for this error.

The original article has been corrected.

The online version of the original article can be found at http://dx.doi.org/ 10.1007/s40140-017-0221-x

Jacobo Moreno Garijo

Massimiliano Meineri

Massimiliano.Meineri@uhn.ca

1 Department of Anesthesia and Pain Management, Toronto General Hospital, University Health Network, 200 Elizabeth Street EN 3-400, Toronto, ON M5G 2C4, Canada 